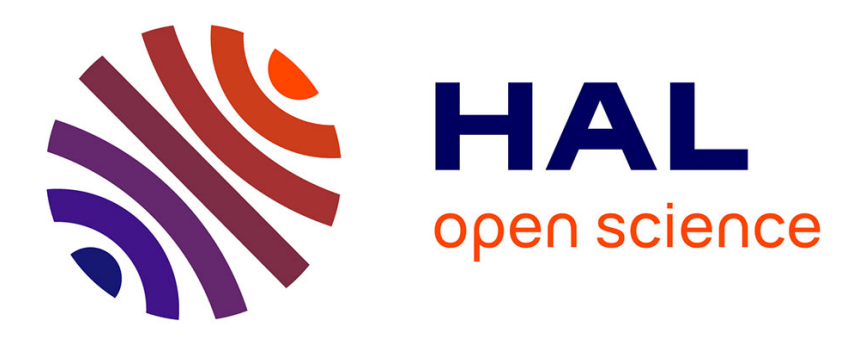

\title{
Dynamic Behavior of High Strength Armor Steels
}

H. Nahme, E. Lach

\section{To cite this version:}

H. Nahme, E. Lach. Dynamic Behavior of High Strength Armor Steels. Journal de Physique IV Proceedings, 1997, 07 (C3), pp.C3-373-C3-378. 10.1051/jp4:1997365 . jpa-00255522

\section{HAL Id: jpa-00255522 https://hal.science/jpa-00255522}

Submitted on 1 Jan 1997

HAL is a multi-disciplinary open access archive for the deposit and dissemination of scientific research documents, whether they are published or not. The documents may come from teaching and research institutions in France or abroad, or from public or private research centers.
L'archive ouverte pluridisciplinaire HAL, est destinée au dépôt et à la diffusion de documents scientifiques de niveau recherche, publiés ou non, émanant des établissements d'enseignement et de recherche français ou étrangers, des laboratoires publics ou privés. 


\title{
Dynamic Behavior of High Strength Armor Steels
}

\author{
H. Nahme and E. Lach* \\ Fraunhofer-Institut Für Kurzzeitdynamik, EMI, Eckerstr. 4, 79104 Freiburg, Germany \\ *Institut Franco-Allemand de Recherches de Saint-Louis, BP.301, 68301 Saint-Louis cedex, France
}

\begin{abstract}
The dynamic properties of the armor steels Mars 190, Mars 240 and Mars 300 have been determined for strain rates $10^{-3} \mathrm{~s}^{-1}<\mathrm{d \varepsilon} / \mathrm{dt}<10^{6} \mathrm{~s}^{-1}$. The planar plate impact technique in combination with a VISAR has been used for high strain rate testing ( $d \varepsilon / d t>10^{4} \mathrm{~s}^{-1}$ ). The dynamic properties Hugoniot-elastic-limit, spall strength, shock velocity-particle verlocity-relation and stress-strain-relation will be presented.

Tests at intermediate strain rates $10^{2} \mathrm{~s}^{-1}<\mathrm{d} \varepsilon / \mathrm{dt}<\mathrm{n} 10^{3}$ have been performed using Taylor tests and a SplitHopkinson-Pressure-Bar (SHPB) setup providing information about strain rate sensitivity, strain hardening and dynamic strength

In addition to the determination of the dynamic properties, the influence of the loading process on the microstructure and the fracture mechanisms have been determined using optical and scanning electron microscopy (SEM).

Résumé. Les propriétés dynamiques des aciers à blindage Mars 190, Mars 240 et Mars 300 ont été déterminées pour des vitesses de déformation $10^{-3}<\mathrm{d} / / \mathrm{dt}<10^{+6} \mathrm{~s}^{-1}$. La technique d'impact plan combinée à celle du VISAR a été utilisée pour les tests à vitesse de déformation élevée $\left(\mathrm{d} \varepsilon / \mathrm{dt}<10^{4} \mathrm{~s}^{-1}\right)$. Les propriétés dynamiques de limite élastique d'Hugoniot, de tension d'écaillage, ainsi que les relations vitesse de choc-vitesse particulaire et contraintedéformation sont présentées. Des tests à vitesse intermédiaire $10^{-2} \mathrm{~s}^{-1}<\mathrm{d} \varepsilon / \mathrm{dt}<\mathrm{n} 10^{3} \mathrm{~s}^{-1}$ ont été réalisés à l'aide d'une installation de barre d'Hopkinson et des essais de Taylor fournissant des informations sur la sensibilité a la vitesse de déformation, l'écrouissage et la contrainte en dynamique. En parallèle avec la détermination des propriétés dynamiques, l'influence des conditions de chargement sur la microstructure et les mécanismes de fracture ont été mis en évidence par microscopie optique et microscopie électronique à balayage (MEB).
\end{abstract}

\section{Introduction}

The steels called Mars ${ }^{1}$ belong to the well known armor steels and are subjected to great attention. The aim of this work is to study the behavior of these steels under loading conditions with strain rates of $10^{-3} \mathrm{~s}^{-1}$ $<\mathrm{d} \varepsilon / \mathrm{dt}<10^{6} \mathrm{~s}^{-1}$. Special interest was given to Mars $300^{2}$. Four different experimental techniques were used to cover this wide range of strain rates. The results serve to evaluate the performance of these steels.

\section{Experimental setup}

Quasistatic compression tests have been performed on a universal testing machine.

Dynamic compression tests were performed using a Split-Hopkinson-Pressure-Bar (SHPB) setup /1/. The bars are of maraging steel with a diameter and length of $20 \mathrm{~mm}$ and $1000 \mathrm{~mm}$ respectively. The striker bars were flat ended to achieve short rise times of the incident signals. Specimens were lubricated with a lubricant on carbon basis. To limit the deformation of the specimens and to protect the bars a stopperring was used. In addition to the SHPB-test direct Taylor impact tests have been performed in the same strain rate region. The Taylor specimens have been $6 \mathrm{~mm}$ in diameter and $40 \mathrm{~mm}$ in length. A rigid target based on tungsten-carbide was used. The velocity of the projectiles was measured by use of a laser light barrier.

The technique used to determine the material properties at strain rates $\mathrm{d} \varepsilon / \mathrm{dt}>10^{4} \mathrm{~s}^{-1}$ was the planar

\footnotetext{
${ }^{1}$ Registered trade mark of Creusot Loire. BP 56.71202 Le Creusot. France. ${ }^{2}$ Creusot Loire patent
} 
plate impact technique in combination with a velocity interferometer system VISAR $/ 2 /$, frequently described in detail elsewhere $/ 3 /$.

Planar plane parallel samples have been impacted by plane parallel projectile plates at velocities between $250 \mathrm{~m} / \mathrm{s}$ and $1050 \mathrm{~m} / \mathrm{s}$. The projectile plates have been accelerated using a single stage compressed air or powder gun. Sample diameter and thickness were $50 \mathrm{~mm}$ and $8 \mathrm{~mm}$ respectively. With a VISAR the velocity time history of the samples rear surface has been recorded with a time resolution of $2 \mathrm{~ns}$.

Impacted samples of Taylor tests and planar impact tests have been recovered softly for post loading examination of the materials microstructure and the spall plane

\section{Material description}

Some static data of the three types of steel studied in this work are listed in Table 1. All materials were quenched and tempered.

Table 1: Properties of Mars armor steels studied

\begin{tabular}{|l|l|l|l|l|}
\hline Type & Description & Hardness $\mathrm{BH} 30$ & $\mathrm{R}_{\mathrm{p} 0.2} / \mathrm{MPa}$ & $\mathrm{R}_{\mathrm{m}} / \mathrm{MPa}$ \\
\hline Mars190 & classic armor steel & $\mathbf{2 7 0 - 4 2 0}$ & $\mathbf{1 0 5 0}$ & $\mathbf{1 1 5 0}$ \\
\hline Mars240 & high strength armor steel & $\mathbf{4 7 0}-\mathbf{5 4 0}$ & $\mathbf{1 3 5 0}$ & $\mathbf{1 7 2 5}$ \\
\hline Mars300 & very high strength armor steel & $\mathbf{7 5 7 5}$ & $\mathbf{1 4 5 0}$ & $\mathbf{2 2 5 0}$ \\
\hline
\end{tabular}

\section{Experimental results}

\subsection{Compression tests}

In Figure 1 the results of the quasistatic and the SHPB-tests are compiled. The flow curves for Mars 300 are the average of two quasistatic tests and five dynamic tests. The dynamic flow curves are adiabatic.

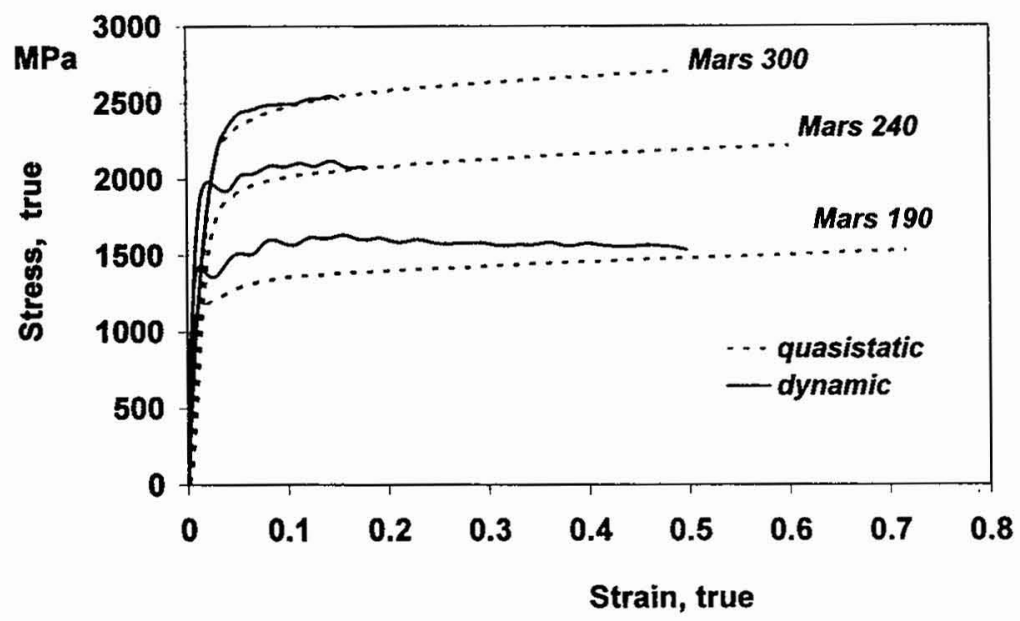

Figure 1: Quasistatic and dynamic flow curves of Mars steels

Quasistatic compression tests show increasing strength with increasing material hardness. Strain hardening for Mars 190 and Mars 240 is nearly equal, but Mars 300 possesses a slightly higher hardening coefficient.

Dynamic compression tests also show increasing strength with increasing hardness. Mars190 was studied at strain rates around $4800 \mathrm{~s}^{-1}$. A strain rate sensitivity has been found for this material resulting in an increase of the flow curve of around $20 \%$ compared to the quasistatic value. Mars 240 was studied at strain rates around $3800 \mathrm{~s}^{-1}$. Its dynamic flow curve possesses a much smaller strain rate hardening. After $15 \%$ deformation the quasistatic and dynamic flow curves of Mars 240 are equal. 
Mars 300 was dynamically tested at strain rates ranging from $1500 \mathrm{~s}^{-1}$ to $2500 \mathrm{~s}^{-1}$. For this steel a low strain rate sensitivity is effective during the first $10 \%$ of the deformation only. Mars 300 tends strongly to adiabatic shear bands under dynamic load. Specimens will be destroyed after $15 \%$ to $20 \%$ of deformation.

Taylor tests were performed to confirm the dynamic compression tests of Mars 300. Dynamic flow stress was calculated by the equation of Taylor. The results are given in table 2 . Values for the dynamic flow stress calculated from the Taylor tests are in good agreement with the results obtained from the SHPB-measurements. Difficulties to determine the exact location of the elastic plastic front causes an uncertainty of about $200 \mathrm{MPa}$. The ratio of final $\left(\mathrm{L}_{\mathrm{f}}\right)$ to initial $\left(\mathrm{L}_{\mathrm{i}}\right)$ length is also given in table 2 . The sample length did not change much during compression. Deformation confined itself mainly to mushrooming. For a projectile velocity of $242 \mathrm{~m} / \mathrm{s}$ the mushroomed zone fractured.

Table 2: Results of Taylor tests on Mars300

\begin{tabular}{|l|l|l|l|l|l|}
\hline specimen & 1 & 3 & 5 & 6 & 7 \\
\hline $\mathrm{V}_{0} \mathrm{~m} / \mathrm{s}$ & $\mathbf{1 3 5}$ & $\mathbf{1 7 0}$ & $\mathbf{1 9 0}$ & $\mathbf{2 1 0}$ & $\mathbf{2 1 6}$ \\
\hline $\mathrm{Y}_{0} \mathrm{MPa}$ & $\mathbf{2 5 0 0}$ & $\mathbf{2 5 4 5}$ & $\mathbf{2 4 6 0}$ & $\mathbf{2 4 0 0}$ & $\mathbf{2 4 1 0}$ \\
\hline $\mathrm{L}_{\mathrm{f}} \mathrm{L}_{\mathrm{i}}$ & $\mathbf{0 . 9 7 8}$ & $\mathbf{0 . 9 6 5}$ & $\mathbf{0 . 9 5 5}$ & $\mathbf{0 . 9 4 3}$ & $\mathbf{0 . 9 4 0}$ \\
\hline
\end{tabular}

In fig. 2 typical velocity profiles from the plate impact tests are displayed for different impact velocities. All signals show the elastic procursor and the velocity increase due to the plastic wave, followed by a very pronounced pull back signal caused by pressure release waves emanating from the projectiles rear surface. In the case of Mars 190 and Mars 240 no spallation was observed at the low impact velocities shown. These velocity histories show a pure "ringing in target" signal with pressure and release waves propagating

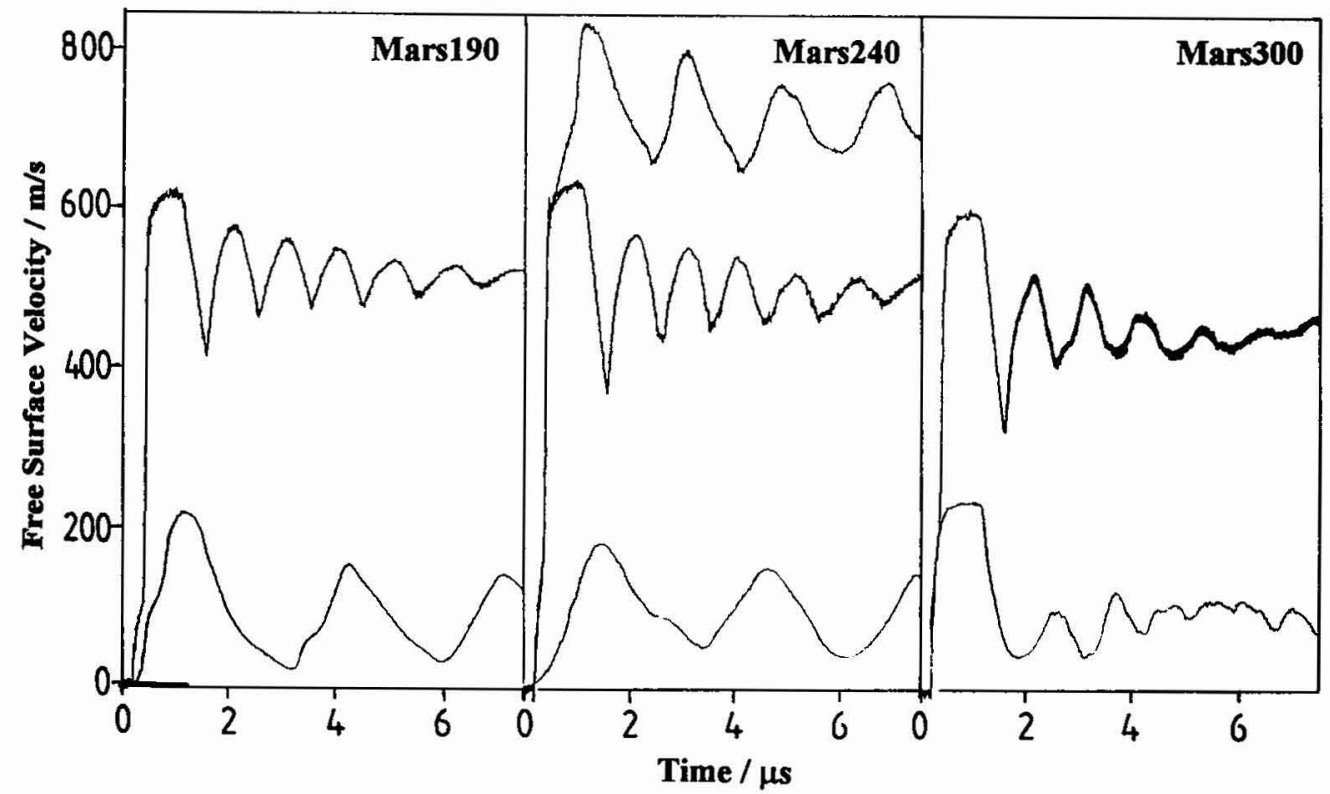

Figure 2: $\quad$ Velocity-time-histories for Mars steels from planar plate impact experiments

back and forth through the whole sample thickness. The low velocity signal for Mars 300 shows indications for a stepwise evolution of the spall plane with a superposition of both a "ringing in target" and "ringing in spall" signal in the beginning and a pure ringing in spall signal after several microseconds. For high velocity tests pure spall signals are observed. For Mars 240 a phase transition signal has been observed at the highest inpact velocity. The phase transition is indicated by the kink in the velocity increase around $600 \mathrm{~m} / \mathrm{s}$.

The dynamic material data Hugoniot-elastic-limit and spall strength, determined from the velocity curves using standerd data reduction methods, are listed in Table 3. 
Table 3: Dynamic material properties of Mars steels from planar plate impact experiments

\begin{tabular}{|l|l|l|l|}
\hline Property & Mars190 & Mars240 & Mars300 \\
\hline Hugoniot-elastic limit $/ \mathrm{GPa}$ & $\mathbf{1 . 2}-\mathbf{2 . 0}$ & $\mathbf{1 . 2}$ & $\mathbf{1 . 6}-\mathbf{2 . 2}$ \\
\hline Spall strength $/ \mathrm{GPa}\left(\mathrm{v}_{0}<700 \mathrm{~m} / \mathrm{s}\right)$ & $\mathbf{4 . 5}$ & $\mathbf{5 . 9}$ & $\mathbf{5 . 7 - 6 . 2}$ \\
\hline Spall strength $/ \mathrm{GPa}\left(\mathrm{v}_{0}>700 \mathrm{~m} / \mathrm{s}\right)$ & $\mathbf{3 . 1}$ & $\mathbf{3 . 4}$ & -- \\
\hline
\end{tabular}

The spall strengths of Mars 240 and Mars 300 of nearly $6 \mathrm{GPa}$ are among of the highest values measured so far. Compared to the quasistatic tensile strength (Table 1) the materials show a very pronounced increase of the spall strength at high strain rates. There seems to be a significant reduction of the spall strength when the impact velocity exceeds $700 \mathrm{~m} / \mathrm{s}$. It has to be confirmed by additional experiments whether this is true and is related to the phase transition observed at highest impact velocity for Mars 240

The shock velocity was calculated from the time interval between the velocity increase due to the respective elastic and plastic wave. The resulting $\mathrm{U}_{\mathrm{S}}-\mathrm{u}_{\mathrm{p}}$ diagram is displayed in figure $3 \mathrm{a}$. The shock velocity remains constant for Mars 300 within the velocity range tested here. This result is surprising because for most metals an increasing particle velocity results in increasing shock velocity. On the other hand for brittle materials like various ceramics and high hardness steels like Maraging Steel (Vaxcomax) for impact velocities below $1000 \mathrm{~m} / \mathrm{s}$ a negative slope of the $U_{\mathrm{S}}-u_{p}$-relation was observed $/ 4 /$. As we know the reason for this behavior is not yet fully understood. From the microscopic examination of impacted samples and fracture surfaces, a quite brittle behavior of Mars 300 is found for samples tested at high strain rates. This may result in the slope of $S=0$ of the $U_{S}-u_{p}$-relation, indicating a position of Mars 300 between the ductile metals and the really brittle materials like ceramics.
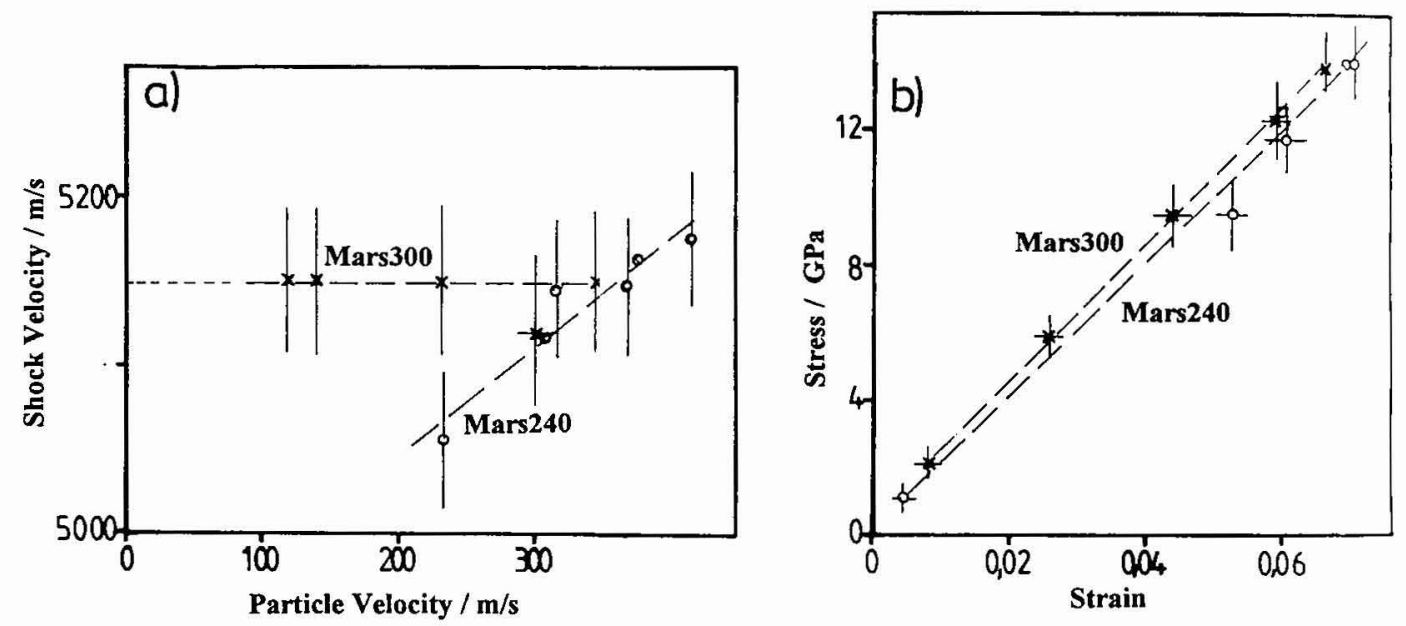

Figure 3: $\quad$ a) Shock-velocity vs particle-velocity diagram for Mars300

b) Stress-strain diagram for Mars 300

A stress-strain diagram for the plate impact data is given in figure $3 b$. Each data point is the result of a single test and is thus influenced by a different strain rate.

\subsection{Microstructure and fracture mechanisms}

Recovered samples have been cut, polished and etched to gain information about the influence of the loading and unloading processes on the microstructure. Figure $4 \mathrm{a}$ shows the micrograph of a fragment from a Mars 300 Taylor test sample. Dynamic loading caused a high density of adiabatic shear bands within the fractured zone. Very similar arrangements of these bands have been found at the edges of plate impact samples impacted at higher velocities. The pattern of these cracks and shear bands is the result of the complex stress distribution within the areas near the sample edge or near the fracture surface of the broken Taylor specimen. 

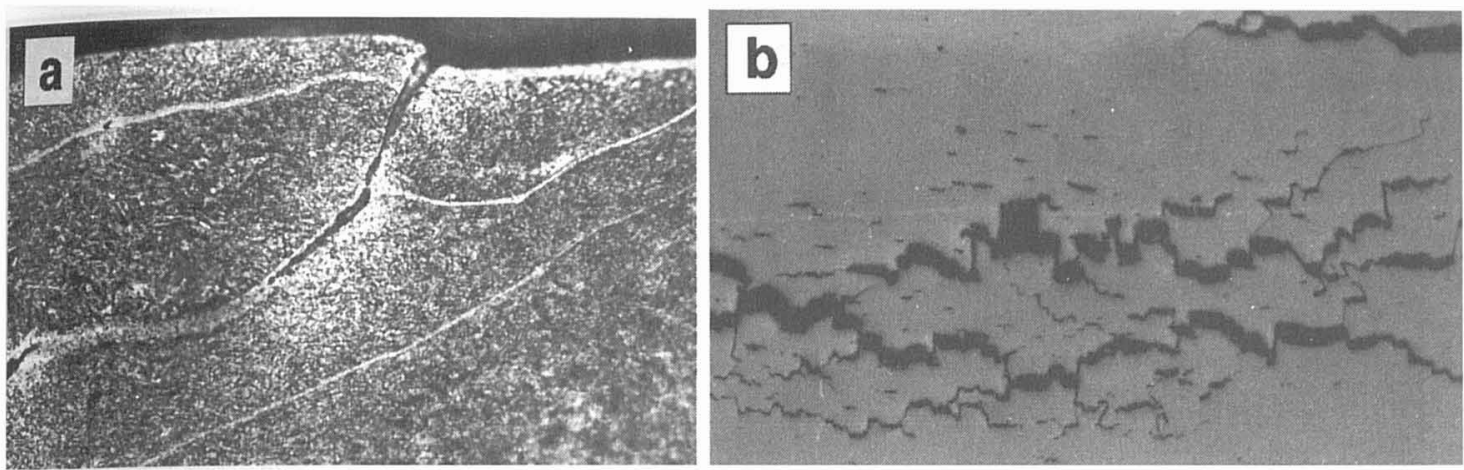

Figure 4:

a) Adiabatic shear bands in Mars 300 Taylor specimen fragment. Scale 500:1

b) Spall cracks in Mars 300 (cracks are in addition to the main spall plane), Scale 22:1

A different distribution of cracks and adiabatic shear bands is found within the central parts of the plate impact specimens. Release waves which are created by reflection of pressure waves at the free surfaces of the sample and the projectile are plane waves causing pure tension stress, when they superpose inside the sample. Besides the main spall plane, caused by the tension stress when it exceeded the dynamic tensile strength of the materials, most samples show additional spall cracks parallel to the flat sample surfaces (Fig. 4b). This indicates a non homogeneous spall strength across the sample thickness and may be connected to the lines of segregation visible in the microstructure.

In all cases these small cracks of a few mm length are connected by cracks perpendicular to the sample surfaces, i.e. parallel to the loading direction.

Micrographs of the white lines found in etched samples show clearly, that the cracks parallel to the loading direction are accompanied by shear failure (fig. 5). The same distinction between the two types of cracks can be made from SEM-pictures of the spall plane surfaces. In fig. 6 two regions of completely different appearance are visible in the region of shear failure.

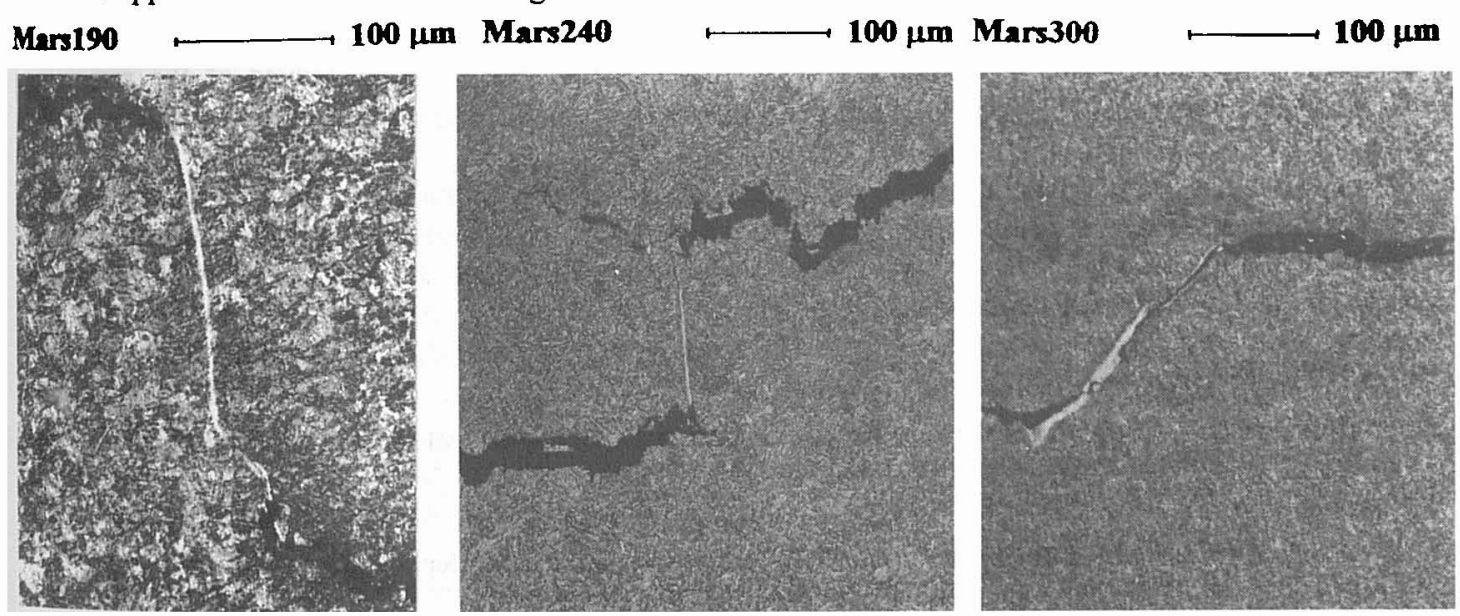

Figure 5:

Adiabatic shear bands in Mars-steels subjected to plane tensile stress during plate impact test

The hardness of the Mars 300 specimen was found to be between $615 \mathrm{HV}_{30}$ and $650 \mathrm{HV}_{30}$. Neither under quasistatic nor under dynamic test conditions of medium strain rates a significant change of the hardness was noticed. For samples subjected to strain rates above $5^{*} 10^{5} \mathrm{~s}^{-1}$ microhardness measurements yielded values of $670-750 . \mathrm{HV}_{0.1}$ of the bulk material and of $850 \mathrm{HV}_{0.1}$ within an adiabatic shear band.

From the microstructural features together with the spall signatures of the velocity curve taken for the lowest impact velocity for Mars 300, a mechanism of the spall process seems plausible which has been observed in a similar way in brass before $/ 3 \%$ : 


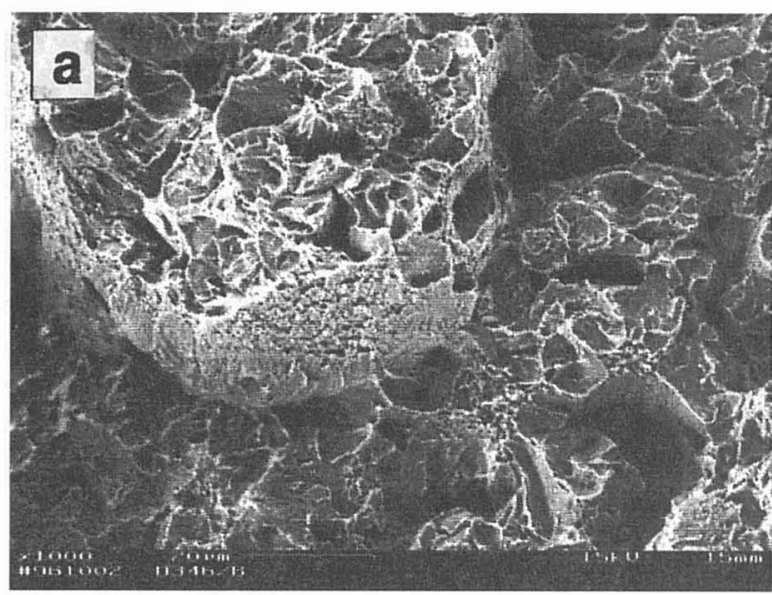

Figure 6: $\quad$ SEM-micrographs of adiabatic shear bands

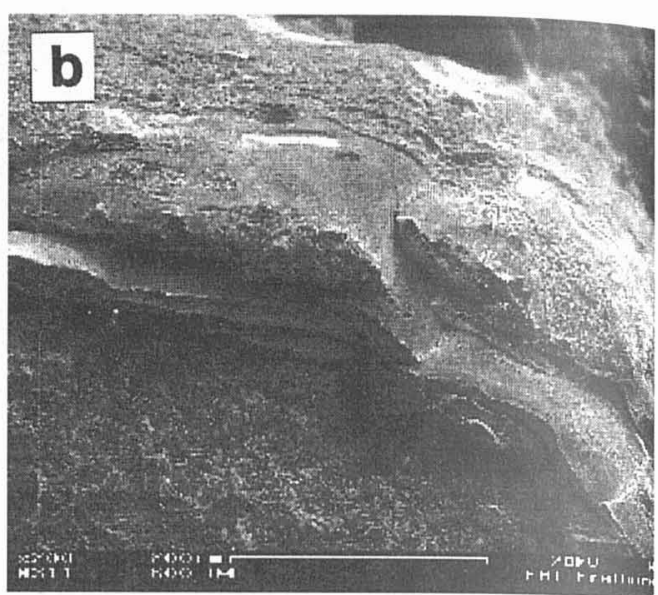

$\begin{array}{ll}\text { a) Mars } 240 & \text { b) Mars } 300\end{array}$

The velocity curve of fig. 2 shows both the "ringing in target" and "ringing in spall" signature, indicating, that the spall process was not completed in a single step but in two distinct steps.

During the first step, tension stress, due to the superposition of release waves inside the sample caused small cracks parallel to the flat sample surfaces. The crack distribution of fig. $4 \mathrm{~b}$ indicates that the lines of segregation resulted in a non homogeneous tensile strength across the thickness of the sample so that small cracks parallel to the surfaces may have evolved wherever the tensile stress exceeded the local material tensile strength. Between these cracks parts of the sample remained undamaged through which parts of the reverberating waves were transmitted while the rest of the waves was reflected at the cracks developed so far. This results in a superposition of the "ringing in target" and "ringing in spall" signals, visible in the velocitiy time history immediately after the spall process starts. In this case the duration of the tensile stress state did not last long enough to complete the spall process. At a later time when tensile stress acted on these weakened areas again, the existing cracks are connected due to shear failure of the remaining material completing the spall process. From this time on, the velocity signal is a pure "ringing in spall". signal.

At higher impact velocities resulting in higher stresses and higher strain rates, the two steps described follow each other with a very short time interval so that they cannot be observed separately in the velocity curve. Nevertheless, the microscopic examination clearly shows the same type of cracks, with a strongly increased number of adiabatic shear bands.

\section{Acknowledgements}

The authors acknowledges Creusot Loire for supporting this work with materials and information.

\section{References}

/1/ Lichtenberger, A. Gazeaud, G. and Lach, E. „Essais de compression sur barres d'Hopkinson“ DYMAT 88, Ajaccio, France, Sept. 19-23. 1988, pp. 589 - 594

/2/ Barker, L.M., Hollenbach, R.E., J. Appl. Phys. Volume 43 (1972), pp. $4669-4675$

13/ Nahme, H., Worswick, M.J., „Dynamic properties and spall plane formation of brass"

EURODYMAT 94, Oxford, UK, Sept. 26-30. 1994, pp. $707-712$

/4/ Marsh, S.P. (ed.) „LASL Shock Hugoniot Data", Univ. of California Press 1980, p. $218 \mathrm{ff}$ 